\title{
Practical working guideline and phantom simulation for radiotherapy during the outbreak of COVID-19 in the Republic of Korea
}

\author{
Eun Kyung Paik ${ }^{1}$, Won Il Jang ${ }^{1 *}$, Chang-Youn Park ${ }^{2}$, Eunji Kim ${ }^{1}$, Sang-Hyoun Choi ${ }^{3}$ and Soon-Sung Lee ${ }^{3}$ \\ ${ }^{1}$ Department of Radiation Oncology, Korea Institute of Radiological and Medical Sciences, Seoul, Korea \\ ${ }^{2}$ External Strategy Team, Korea Institute of Radiological and Medical Sciences, Seoul, Korea \\ ${ }^{3}$ Research Team of Radiological Physics \& Engineering, Korea Institute of Radiological and Medical Sciences, Seoul, Korea
}

The World Health Organization on March 11, 2020, has declared the novel coronavirus (COVID-19) outbreak a global pandemic. As of December 29,2020, the accumulated number of confirmed cases is over $79,600,000$ with $1,760,000$ deaths worldwide due to COVID-19 and these numbers rise by the day. The most effective means to minimize the spread of the virus is social distancing, which is designed to reduce the amount of interactions between individuals, according to the Centers for Disease Control. This practical working experience show our radiotherapy treatment process during the outbreak of COVID-19. We present the present work give some idea to radiation oncologists managing cancers patients with radiotherapy during the outbreak of COVID-19 in order to minimize the risks to our patients and staff while maintaining cancer outcomes.

\section{Our radiotherapy treatment process during the out- break of COVID-19 (Table 1)}

A. Patients may continue radiotherapy only in selected cases, if their general medical conditions are not compromised by COVID-19 infection, if the oncological condition requires continuation of radiotherapy and with the use of adequate disposable protective equipment or negative pressure isolation stretcher. Provide a hydroalcoholic solution for hand disinfection at the entrance of the radiotherapy center. Wear surgical masks, as recommended for all health professionals and patients according to WHO indications.

B. Screening for COVID-19 infection is ongoing at the entrance gate for outpatients, and at the ward for inpatients, and there were no confirmed cases at our hospital yet. Currently, confirmed cases are not being managed at our hospital, therefore radiotherapy treatment will not be initiated for confirmed cases.

C. However, COVID-19 transmission can occur to patients while undergoing radiotherapy treatment, and in some cases may require continued treatment. To prepare for cases in need of radiotherapy treatment in COVID-19 patients, a radiotherapy feasibility study was conducted.

D. The CT simulation process was carried out with a thorax phantom inside a negative pressure isolation stretcher. A clear negative pressure isolation stretcher with portals for gloves was used during the process, making it possible to adjust the placement of the phantom (or the patient) without blockage of the laser beams for positioning. Also, with this equipment being used during treatment, there is no need for the staff to wear personal protection equipment (PPE) other than the basic surgical mask during the entire process of patient encounter. After the treatment of COVID-19 positive patients (or patients waiting for diagnostic confirmation), there is no need to sanitize the waiting and bunker areas at the end of the treatment session. If possible, these patients should be treated at the end of the LINAC shift to limit the chances of infection for other patients. An additional CT scan of the phantom without the negative pressure isolation stretcher was performed to calculate and compare the dose distributions of the two cases (Figure 1).

E. Likewise, the CT simulation process was carried out with a 3-dimensional (3D) printed anthropomorphic phantom inside a negative pressure isolation stretcher. An additional CT scan of the phantom without the negative pressure isolation stretcher was performed to calculate and compare the dose distributions of the two cases (Figure 2).

2. Comparison of the radiotherapy treatment plans between cases with and without the negative pressure isolation stretcher

A. Treatment plans for thorax phantom cases with and without the negative pressure isolation stretcher are on the right and left of the figure respectively. The DVH curve is shown in the middle, with the square representing cases with the negative pressure isolation stretcher and the triangle representing cases without it (Figure 3).

B. The total dose has decreased about $2.6-2.8 \%$ with the usage of the negative pressure isolation stretcher, mostly affected in the PA direction. It does not seem to be a significant discrepancy to avoid treatment when absolutely needed (Figure 4).

C. Treatment plans for anthropomorphic phantom cases with and without the negative pressure isolation stretcher are on the right and left of the figure respectively. Similar to thorax phantom cases, the

${ }^{\star}$ Correspondence to: Won Il Jang, MD, Department of Radiation Oncology, Korea Institute of Radiological \& Medical Sciences, 75 Nowon-ro, Nowon-gu, Seoul 01812, Republic of Korea, Tel: $+82-2-970-1262$, Fax: $+82-2-970-2412$, E-mail: zzang11@kirams.re.kr

Received: September 29, 2020; Accepted: October 15, 2020; Published: October 18,2020 
Table 1. Radiotherapy treatment process during the outbreak of COVID-19

\begin{tabular}{|c|c|c|c|c|c|}
\hline & $\begin{array}{l}\text { History of visit and } \\
\text { contact }\end{array}$ & $\begin{array}{l}\text { Symptoms (fever, } \\
\text { respiratory disease ) }\end{array}$ & Entrance control center & COVID-19 test & Radiotherapy \\
\hline \multirow{10}{*}{$\begin{array}{l}\text { New } \\
\text { patients }\end{array}$} & \multirow{6}{*}{ Yes } & \multirow{3}{*}{ Yes } & \multirow{3}{*}{ Screening Center } & In progress & Postpone \\
\hline & & & & Positive & Postpone \\
\hline & & & & Negative & Treatment in progress \\
\hline & & \multirow{3}{*}{ No } & \multirow{3}{*}{ Screening Center } & In progress & Postpone \\
\hline & & & & Positive & Postpone \\
\hline & & & & Negative & Treatment in progress \\
\hline & \multirow{4}{*}{ No } & \multirow{3}{*}{ Yes } & \multirow{3}{*}{ Screening Center } & In progress & Postpone \\
\hline & & & & Positive & Postpone \\
\hline & & & & Negative & Treatment in progress \\
\hline & & No & \multicolumn{3}{|l|}{ Treatment in progress } \\
\hline \multirow{10}{*}{$\begin{array}{l}\text { Patients } \\
\text { on RT }\end{array}$} & \multirow{6}{*}{ Yes } & \multirow{3}{*}{ Yes } & \multirow{3}{*}{ Screening Center } & In progress & Postpone \\
\hline & & & & Positive & Postpone or negative pressure cart* \\
\hline & & & & Negative & Treatment in progress \\
\hline & & \multirow{3}{*}{ No } & \multirow{3}{*}{ Screening Center } & In progress & Postpone \\
\hline & & & & Positive & Postpone or negative pressure cart* \\
\hline & & & & Negative & Treatment in progress \\
\hline & \multirow{4}{*}{ No } & \multirow{3}{*}{ Yes } & \multirow{3}{*}{ Screening Center } & In progress & Postpone \\
\hline & & & & Positive & Postpone or negative pressure cart* \\
\hline & & & & Negative & Treatment in progress \\
\hline & & No & \multicolumn{3}{|l|}{ Treatment in progress } \\
\hline
\end{tabular}

* Decided by personalized clinical assessment.
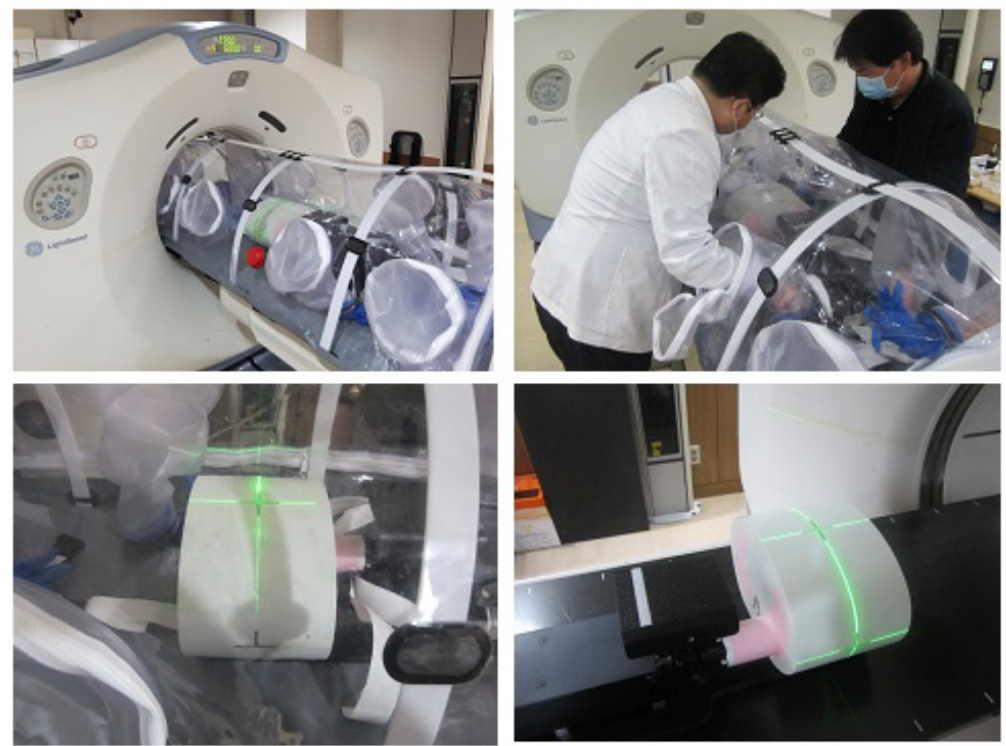

Figure 1. CT simulation with a thorax phantom inside a negative pressure isolation stretcher

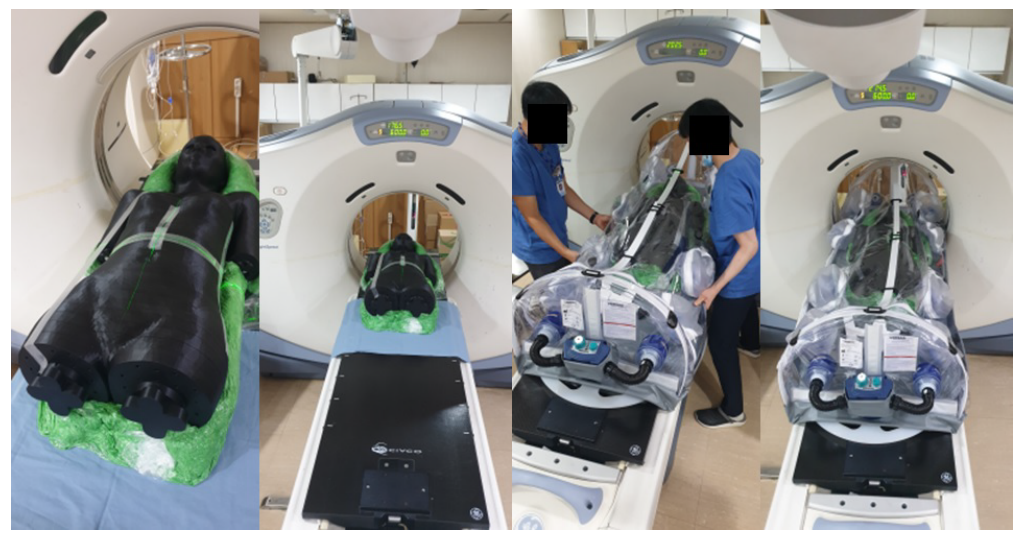

Figure 2. CT simulation with a 3-dimensional printed anthropomorphic phantom inside a negative pressure isolation stretcher 


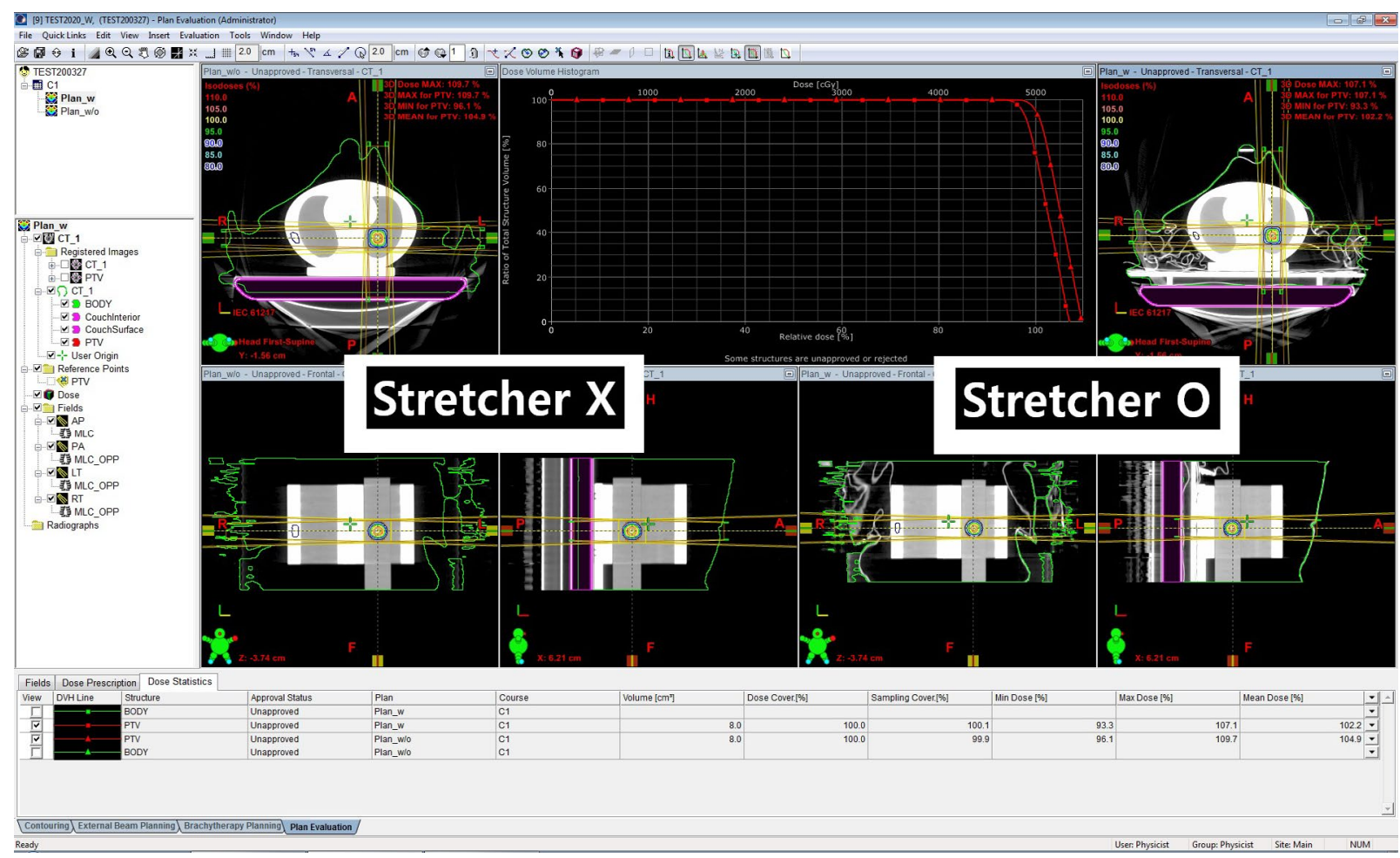

Figure 3. Comparison of radiotherapy treatment plans between a thorax phantom inside (right sided images) and outside (left sided images) a negative pressure isolation stretcher
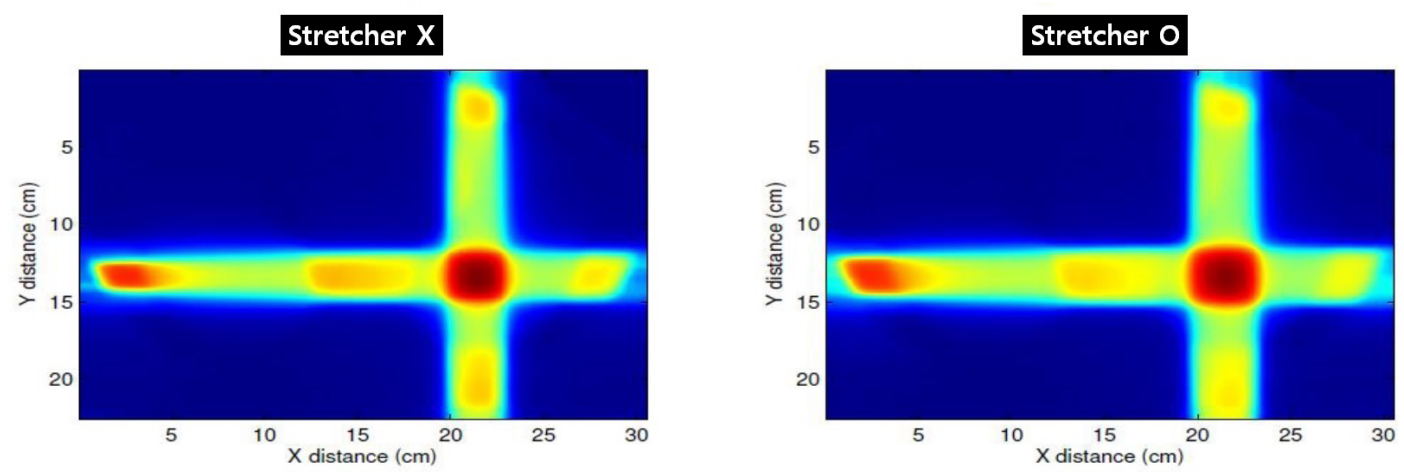

<Dose comparison>

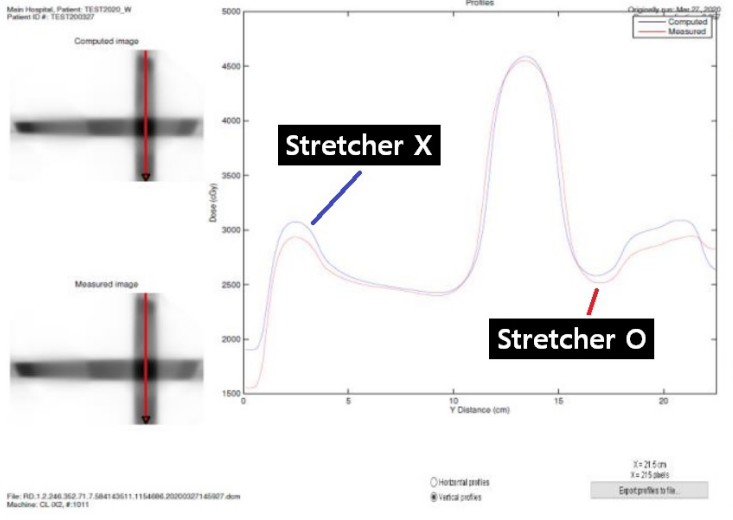

$<$ Vertical profile comparison>

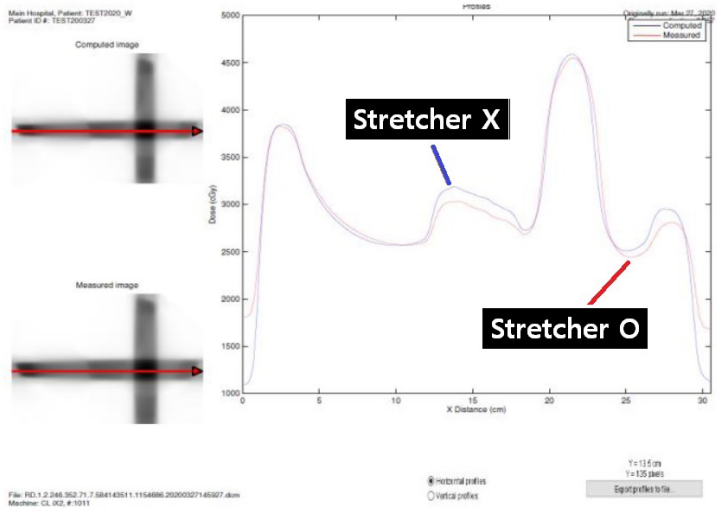

$<$ Horizontal profile comparison>

Figure 4. Isodose curve, vertical profile, and horizontal profile comparison between a thorax phantom inside and outside a negative pressure isolation stretcher 


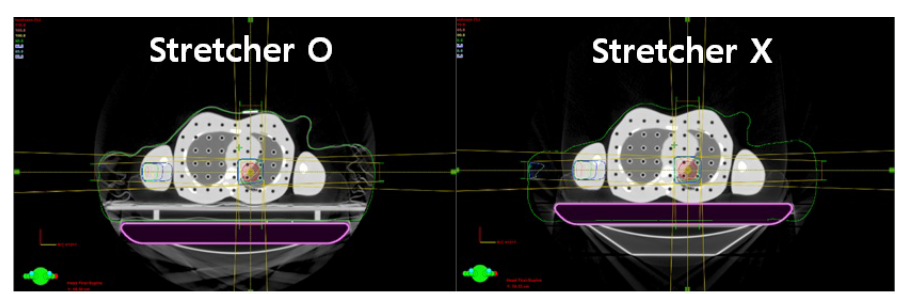

\begin{tabular}{|c|c|c|c|c|c|}
\hline \multicolumn{2}{|c|}{ Min Dose(\%) } & \multicolumn{2}{c|}{ Max Dose(\%) } & \multicolumn{2}{c}{ Mean Dose(\%) } \\
\hline Stetcher O & Stetcher X & Stetcher O & Stetcher X & Stetcher O & Stetcher X \\
\hline 94.7 & 97.5 & 106.7 & 109.3 & 101.5 & 103.9 \\
\hline \multicolumn{2}{c|}{$-2.8 \%$} & $-2.6 \%$ & $-2.4 \%$ \\
\hline
\end{tabular}

Figure 5. Comparison of radiotherapy treatment plans between a 3-dimensional printed anthropomorphic phantom inside (left sided image) and outside (right sided image) a negative pressure isolation stretcher

total dose for anthropomorphic phantom cases has decreased about $2.4-2.8 \%$ with the usage of the negative pressure isolation stretcher. It does not seem to be a significant discrepancy to avoid treatment when absolutely needed (Figure 5).

\section{Availability of data and materials}

The datasets used during the current study are available from the corresponding author on reasonable request.

\section{Competing interests}

The authors declare that they have no competing interests.

\section{Funding}

This study was supported by a grant of the Korea Institute of Radiological and Medical Sciences (KIRAMS), funded by the Ministry of Science and ICT (MSIT), Republic of Korea. (no. 50432-2020).

\section{Authors' contributions}

WIJ contributed to study concepts, study design, literature research, data acquisition, data analysis, data interpretation, manuscript preparation and manuscript editing. EP, EK, and $\mathrm{CP}$ contributed to study concepts, study design, manuscript preparation and manuscript editing. SC and SL contributed to perform the radiotherapy simulation, treatment planning, planning evaluation, and dosimetric data comparison. All authors read and approved the final manuscript.

\section{References}

1. World Health Organazation Coronavirus Disease (COVID-19) Dashboard. [https:// covid19.who.int/]. Data last updated: 2020/12/28, 4: 56pm CET

2. Achard V, Tsoutsou P, Zilli T (2020) Letter from Switzerland: Radiotherapy in the time of the Coronavirus pandemic: when less is better. Int J Radiat Oncol Biol Phys 107 600-601. [Crossref]

3. Marijnen CAM, Peters FP, Rödel C, Bujko K, Haustermans K, et al. (2020) International expert consensus statement regarding radiotherapy treatment options for rectal cancer during the COVID 19 pandemic. Radiother Oncol 148: 213-215. [Crossref]

4. Tchelebi LT, Haustermans K, Scorsetti M, Hosni A, Huguet F, et al. (2020) Recommendations on the use of radiation therapy in managing patients with gastrointestinal malignancies in the era of COVID-19. Radiother Oncol 148: 194-200. [Crossref]

5. Guckenberger M, Belka C, Bezjak A, Bradley J, Daly ME, et al. (2020) Practice recommendations for lung cancer radiotherapy during the COVID-19 pandemic: An ESTRO-ASTRO consensus statement. Radiother Oncol 146: 223-229. [Crossref]

6. Braunstein LZ, Gillespie EF, Hong L, Xu A, Bakhoum SF, et al. (2020) Breas radiotherapy under COVID-19 pandemic resource constraints -- approaches to defer or shorten treatment from a Comprehensive Cancer Center in the United States. $A d v$ Radiat Oncol 5: 582-588. [Crossref]

7. Wei W, Jiang H, Chen W, Zhou Y, Guo S, et al. (2020) How should we implement radiotherapy for cancer patients in China during the endemic period of COVID-19? Radiother Oncol 147: 100-102. [Crossref]

8. Filippi AR, Russi E, Magrini SM, Corvò R. (2020) COVID-19 Outbreak in Northern Italy: First Practical Indications for Radiotherapy Departments. Int J Radiat Oncol Biol Phys 107: 597-599. [Crossref]

Copyright: (C2020 Paik EK. This is an open-access article distributed under the terms of the Creative Commons Attribution License, which permits unrestricted use, distribution, and reproduction in any medium, provided the original author and source are credited. 